\title{
Revising the Curricula of Higher Education to Connect to the Job Market: An Approach Based on Job Description Mining
}

\author{
Zhixuan Chen ${ }^{*}$ \\ School of Management, Guangzhou City Institute of Technology, Guangzhou 510800, China \\ ${ }^{*}$ Corresponding author. Email: chenzx@gcu.edu.cn
}

\begin{abstract}
For sustainability to realize its full transformative potential in higher education and society, it must connect sustainability skills and competences to the job market and to enable future as well as current practitioners and decision makers to become agents of transition toward Sustainability. This paper presents a new method to quickly extract job knowledge base and capability requirements from job description text, which is based on word vector search semantics obtained by skip-gram neural network model. It further comparative analyses the capability needs found with the current curriculum system and then revises the curriculum of higher education. Compared with the traditional questionnaire survey method, this method has the advantages of quickly and accurately reflecting the needs of commercial society for workers and quickly extracting the abilities needed, and provide some references for universities to revise curricula with and promote the realization of the Sustainable Development Goals.
\end{abstract}

Keywords: Job Description, Curriculum Revision, Knowledge Base, Semantics Analysis, Word Vector.

\section{INTRODUCTION}

Today's society, from governments to businesses and citizens, faces very complex social, political, economic and environmental challenges. In the face of these challenges, on September 2015, all 193 United Nations (UN) member states formally adopted the United Nations' 2030 Agenda that represents an agreement between all UN Member States to introduce a set of common strategies to achieve 17 goals (the Sustainable Development Goals, or SDGs) and 169 targets before the year 2030. The 17 goals cover several areas, including economic, social and environmental issues [1]. These 17 goals can no longer be dealt with in a separate and independent way but must be achieved in a cross-cutting manner, with all individuals, companies, private and public organizations and institutions, and governments, bearing their shares of responsibility[1][2]. In this sense, higher education should play an important role in the development of these goals, as they are important promoters of the overall development of future citizens and have the responsibility to cultivate the sustainable development capacity of student groups and communities[3][4]. This requires that the training goal and direction of higher education be consistent with the needs of social development. The curriculum is an important means to achieving training objectives, and the selection of relevant courses is the link between education and society.

The traditional business curriculum generally pays attention to the knowledge structure system of the subject, but ignores the needs of the current businesses in society. These deficiencies are mainly reflected in: (1) the lack of connection between knowledge and business skills; (2) insufficient understanding of business needs; (3) the fact that it takes a long time to integrate requirements into the curriculum and form a capable training system. There are several reasons for this state of affairs. Further analysis shows that one of the important reasons is that traditional survey methods, such as expert interviews and extensive questionnaire surveys, not only require huge financial resources, but also take a long time to collect and analyze, as does refining the knowledge and integrating it into the course. Therefore, how to quickly and accurately meet the demands of businesses for workers, and thus quickly learn how to teach the abilities needed, has become an urgent problem to be solved in higher education.

The requirements of the business community for new employees can be obtained through job advertisements. 
Semantics means to extract knowledge and capabilities from the job descriptions and establish connections among them, forming a keyword-centered correlation in a knowledge base. Therefore, it is of great academic value and practical value to seek this kind of correlation map for necessary skills quickly and accurately, so that we may apply it to a course. This paper proposes using deep learning technology to quickly extract accurate job description information, and to then establish the relationships between knowledge taught and abilities needed. The corresponding relationships of the knowledge base and abilities demanded provide the basis for connecting curriculum revision to social demand.

The structure of this paper is as follows. After this brief introduction, in Section 2, we will briefly review the text mining and the main concepts of the knowledge base. In Section 3, we introduce the research design for extracting textual semantics. In Section 4, we present and explain the research results of textual semantic extraction based on job description information. Section 5 presents the main conclusions.

\section{RELATED WORK}

\subsection{Text Mining}

Recruitment information or job description text contains the knowledge and abilities needed for the position. Mining the semantic relationships of such text is helpful for understanding the actual demands of each position, which is also the key to semantic searching. As the recruitment information belongs to the short text, and because the short-text information is sparse, intelligent processing and analysis are more complex. At present, in the field of natural language processing, scholars are exploring the use of deep learning. Deep learning mainly involves complex neural networks or multiple non-linear functions in multiple data processing layers[5]; initially, deep learning focused on the field of image and voice recognition, and was then used in natural language processing (natural language processing, or NLP). Deep learning in the field of NLP benefits from the research of Hinton and Salakhutdinov (2006) [6] in deep learning in text analysis. Before that, in order to measure the semantic similarity between texts, Harris (1954) [7] proposed the distributional hypothesis, that is, "words with similar context also have similar semantics," which provided the theoretical basis for the distributional representation of words. Brown et al. (1992) [8] also constructed a context clustering model based on the distribution hypothesis, and pioneered the distribution representation method based on clustering. Dagan et al. (1993, 1999) [1][10] summarized and perfected the method of meaning representation by context distribution and applied the representation to tasks such as word sense disambiguation, which was then called word space model. Bengio et al. (2003) [11] formally proposed the neural network language model (NLM). The model not only learns the language model, but also gets the word vector. In the case of no manual involvement in the design of effective features, the learning method achieves equivalent or better performance compared with the traditional supervised model (Lai et al., 2013) [12].

\subsection{Knowledge Base}

A knowledge base belongs to the category of scientometrics. The rise of scientific metrology research can be traced back to the 1960s, to de Solla Price. Over 50 years of scientometrics, analysis has moved from the traditional statistical analysis, to the evolution of computer-aided analysis and map-based visualization analysis. The development of computer science and technology played an important role. Hall and O'Donnell (1996) [14] studied the role of knowledge graphs in teaching and proved through experiments that knowledge graphs can help improve students' learning efficiency. McCain et al. (2005) studied the software engineering field by using the card classification method and the PFNet method, and drew a map of this field [15]. Janssens et al. (2005) [16] used text mining and bibliometric methods combined with Ward's method and the K-value algorithm to analyze selected journals and draw the atlas of the scientific structure of scientometrics. Knowledge mapping is a visualization tool for knowledge resources and their interrelationships [17]. By creating an environment for knowledge sharing within an organization, mapping, mining, analyzing and displaying the interrelationships among knowledge can ultimately achieve the purpose of promoting knowledge exchange and in-depth research [18][19]. Based on visualization technology, the knowledge map arose [20]. The subsequent HRBP model studies the integrated framework of research. In reference [21], they quantitatively showed China's situation of human resource management research [22][23][24]. Thus, it can be seen that the current knowledge base and map analysis research mainly focuses on displaying and applying of relatively macroscopic research hotspots and cuttingedge research trends, but knowledge map analysis based on job descriptions is rarely used to dig out the knowledge and abilities required by jobs so as to help with the curriculum setting of business education.

This paper uses word vectors to reflect the relations between words and semantic features, differently from the traditional means of investigation, such as expert interviews, a wide range of questionnaire surveys and so on. With the help of a neural network model, this paper proposes semantic-level similarity calculations in order to realize the automatic mapping between terms, to form a knowledge base of industry or post library, providing the basis for a curriculum. 


\section{MATERIALS AND METHODS}

\subsection{Materials}

In this paper, the text of 240,000 job descriptions related to e-commerce, data and the Internet was downloaded from the 51job (www.51job.com) recruitment website between September 2016 and August 2020 through web scraping technology. Due to the differences in terms and their different connotations in different industries, job descriptions were classified by industry in order to obtain high-quality word vectors.

A preliminary analysis of the text showed that a job description has the following characteristics: (1) The job description text is relatively short, with about 300--400 words. (2) The text contains a lot of industry terms and language. (3) We found through observations of job description content that these job descriptions pay a lot of attention to the ability requirements and responsibilities of the position. (4) Recruitment information also focuses on expressing the development prospects of the company and the position.

\subsection{Methods}

At present, word vectors are widely used in deep learning processing NLP tasks. A word vector is a distributed means of word representation, which can learn the language information between words from a large number of unlabeled corpora, and can represent the concept of "distance" between words and contain more information, and each dimension has a specific meaning. By learning the text, words can be transformed into vector forms and the semantic information of words can be represented by vector forms. The idea is to embed the words from the original space into a new multidimensional space, so that semantically similar words can be relatively near in space. This process is essentially a form of mapping. Compared with the traditional representation of bag of words (BOW), the word vector has the characteristics of low dimensionality and density.

The Word2Vec training tool was used in this paper. Mikolov et al. (2013) [25] proposed two models, CBOW (continuous bag of words) and skip-gram. The former model predicts target word information based on a given context. The latter expects to predict which words appear in context by entering a word (Figure 1). Although the skip-gram model has high computational complexity, it generally performs better in large corpora with more accurate semantics [26][27]. According to the experimental conclusion of Lai et al. (2013) [13], the effect of the skip-gram model is better than that of the CBOW model when the corpus is small. Due to the short text of each job description and the small amount of data in this study, the skip-gram model was selected for training, and the 50-dimensional word vector was selected for representation.
In order to produce relationships between the knowledge base and ability demands, we have designed a 4-step approach by combining a series of existing analytical practices. The four steps are preparation and preprocessing of the original corpus, training word vectors, semantic clustering and the establishment of a classification knowledge base, as shown in Figure 1.

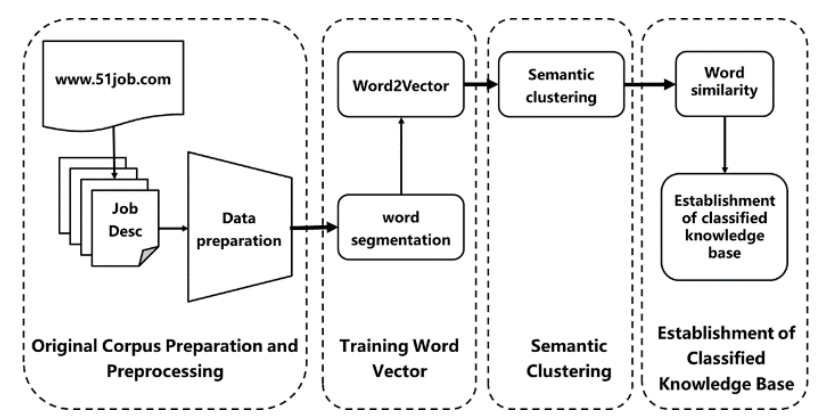

Figure 1 The 4-step approach.

\subsubsection{Preparation of the Original corpus and preprocessing}

There are a variety of search methods in www.51job.com, and you can get cross-industry and cross-field search results from keyword searches of jobs. The research objective of this study was to find semantic differences among different industries or fields in job descriptions. Therefore, the search target of the crawler design was industry, which made it easy to label the same industry with a uniform label. In data preprocessing, the collected job descriptions and resumes were first cleaned of the company names, names and other words pertaining to privacy.

\subsubsection{Training the word vector}

Word2Vec cannot directly recognize Chinese corpora, and text segmentation mainly includes word segmentation, stop-use words and invalid characters. The quality of Chinese word segmentation directly affects the quality of subsequent natural language processing tasks. Current word segmentation algorithms are mainly divided into two types: traditional machine learning models and neural network word segmentation models. Compared with the traditional machine learning model, the neural network word segmentation model does not have significant advantages in word segmentation precision and computational efficiency [28]. The Jieba open source word segmentation tool based on traditional machine learning was selected. Based on a prefix dictionary, this algorithm realizes word graph scanning and generates a directed acyclic graph (DAG) formed by all possible word formations of Chinese characters in sentences. Dynamic programming is adopted to find the maximum probability path and find the maximum segmentation combination based on word frequency, with a good word segmentation effect [13]. For the 
unlogged words, an HMM model based on Chinese character word-forming ability was adopted, and the Viterbi algorithm was used for calculations. Then, stop words and invalid characters (for example, punctuation) were removed by using a stop-words list, and the industry corpus after word segmentation was finally obtained.

In order to obtain high-quality word vectors, the skipgram model in Word2Vec's open source tools was used to train job descriptions classified by industry as a corpus. Finally, a 50-dimensional word vector representation was obtained, which constituted the word vector library. In this step, the packaged Word2Vec interface provided in GENSIM library was used to train the pre-processed corpus, and skip-gram was selected as the model. The parameter settings are shown in Table 1.

Table 1. The parameter settings.

\begin{tabular}{|c|l|c|}
\hline Parameters & \multicolumn{1}{|c|}{ Description } & Value \\
\hline Size & The dimension of the word vector & 50 \\
\hline Window & $\begin{array}{l}\text { The maximum distance between the } \\
\text { current word and the target word }\end{array}$ & 8 \\
\hline Min_count & $\begin{array}{l}\text { Word frequency less than min_count } \\
\text { will be filtered vector }\end{array}$ & 2 \\
\hline Learning_rate & The rate of deep learning & 0.01 \\
\hline iter & The number of iterations & 30 \\
\hline
\end{tabular}

\subsubsection{Semantic clustering}

The key to semantic clustering is the definition of distance between words. In this paper, cosine distance is used, which is defined as:

$$
\cos \theta=\frac{\sum_{i=1}^{n} x_{i} * y_{i}}{\sqrt{\sum_{i=1}^{n} x_{i}^{2} \sum_{i=1}^{n} y_{i}^{2}}}
$$

After the text was trained into word vectors, the similarities with the word vectors of various industries were calculated. One must find each word after text segmentation in the industry corpus, and calculate the similarities of the word vectors of the matching words by summing them up and averaging them. The formula is as follows:

$$
s=\frac{1}{N} \sum_{i=1}^{N} h\left(a_{1 i}, a_{2 i}\right)
$$

where $h$ is a function to calculate the distance between vectors, $N$ is the total number of the same words and $\boldsymbol{\alpha}_{1 i}$ and $\boldsymbol{\alpha}_{2 i}$ respectively represent the values of two word vectors in the $i$-th dimension.

\subsubsection{Establishment of a classified knowledge base}

On the basis of the above, the top 10 terms with the most similarity to the vector cosine of this term were selected for each industry subject. In other words, there were 10 corresponding terms for each keyword to express semantics. This overcame the mismatch of keyword search results due to the use of different terms.

\section{ANALYSIS OF RESULTS}

\subsection{Type of listing}

According to the data of job roles and job descriptions, this study classified the positions of e-commerce talents in enterprises. The demand side of e-commerce talents can be broadly divided into two categories: one is specialized for online-only e-commerce enterprises; the other is general, for traditional enterprises that carry out e-commerce business. There are some differences between the two types of enterprises in the prioritizing of e-commerce talents, which can be divided into three types: technology, business and comprehensive management. See Table 2 for the talents required for each type of position and the specific requirements for each position.

From Figure 2, you can see the different requirements in different spatial locations, such as "database" as the center of the technical terms on the right side of the Figure 2, "management" as the center of the management class is concentrated in the upper left of Figure 2 and "team spirit" is concentrated at the bottom left of Figure 2. It can be further found that, taking "database" as an example, the closest words in the original space can be found to be SQL, Windows, MySQL, database system, Oracle, NoSQL, etc. It can also be seen from Figure 2 that the clustering and distribution trends of related words decreased to three-dimensional space. Through comprehensive observations, it can be seen that the shorter the distance in word vector space between the two words in the figure, the closer the semantic meaning is (the closer the distance is to red, the closer the distance is). This means that the corresponding words usually have similar contexts in the corpus, and are likely to be related. 
Table 2. Job types and descriptions using e-commerce talents.

\begin{tabular}{|c|c|c|}
\hline Position Type & Title & Job Descriptions \\
\hline \multirow[t]{3}{*}{ Technical } & \begin{tabular}{|l} 
E- \\
commerce \\
platform \\
designer
\end{tabular} & $\begin{array}{l}\text { Mainly responsible for the e-commerce operation and operation process of the enterprise's } \\
\text { check-in platform or its own platform, including page design, background management, } \\
\text { advertising design and other work contents. }\end{array}$ \\
\hline & $\begin{array}{l}\text { E- } \\
\text { commerce } \\
\text { website } \\
\text { designer }\end{array}$ & $\begin{array}{l}\text { Mainly responsible for website production, page design, background editing and maintenance, } \\
\text { advertising design and other work content. }\end{array}$ \\
\hline & \begin{tabular}{|l|} 
Business \\
Data \\
Analyst
\end{tabular} & $\begin{array}{l}\text { Mainly responsible for the statistics, analysis and monitoring of the traffic and user behavior } \\
\text { of the platform or website, providing multi-dimensional data analysis services in the two } \\
\text { directions of website data and marketing communication, and putting forward business } \\
\text { strategy suggestions based on the data analysis results. }\end{array}$ \\
\hline \multirow[t]{3}{*}{ Business } & $\begin{array}{l}\text { Customer } \\
\text { service }\end{array}$ & $\begin{array}{l}\text { Mainly responsible for communication with customers, including using online instant } \\
\text { messaging tools to communicate with customers; Deal with customer feedback, } \\
\text { return/exchange, complaint, refund, etc. Inquire customer order express and follow up } \\
\text { logistics information and other work content. }\end{array}$ \\
\hline & \begin{tabular}{|l|} 
Website \\
operation
\end{tabular} & $\begin{array}{l}\text { Mainly responsible for the establishment of enterprise e-commerce channel operation mode, } \\
\text { formulation and implementation of enterprise sales plan and KPI, formulation of activity } \\
\text { planning, daily operation of enterprise online store and other related work content. }\end{array}$ \\
\hline & $\begin{array}{l}\text { Website } \\
\text { promotion }\end{array}$ & $\begin{array}{l}\text { Mainly responsible for the operation and promotion of the enterprise online store, using the } \\
\text { promotion work and methods and social platforms to promote the enterprise brand or product } \\
\text { online, participating in the writing and implementation of enterprise activity planning copy, } \\
\text { customer relationship management and other work contents. }\end{array}$ \\
\hline \multirow[t]{2}{*}{$\begin{array}{l}\text { General } \\
\text { management }\end{array}$} & $\begin{array}{l}\text { E- } \\
\text { commerce } \\
\text { project } \\
\text { manager }\end{array}$ & $\begin{array}{l}\text { Mainly responsible for the development, implementation, evaluation and other related } \\
\text { management work of the enterprise's e-commerce related activities. }\end{array}$ \\
\hline & $\begin{array}{l}\text { e- } \\
\text { commerce } \\
\text { department } \\
\text { Manager }\end{array}$ & $\begin{array}{l}\text { Mainly responsible for the work content of specific departments, including the formulation of } \\
\text { goals and work plans, task allocation and implementation, and department performance } \\
\text { evaluation, etc. }\end{array}$ \\
\hline
\end{tabular}

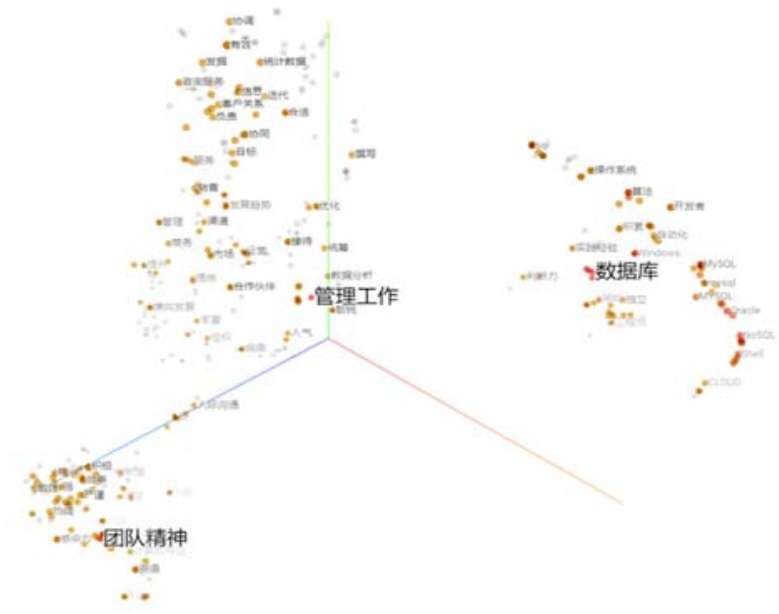

Figure 2 Visualization of word vector reduction in the e-commerce domain. Notes: Since the original data were in Chinese, only Chinese terms are displayed.

In this study, a cosine value between vectors is quantified according to the positions of the word vectors in the semantic space, so as to obtain the knowledge base of the industry. A cosine between vectors is not only an intuitive representation of positional information, but also can reflect semantic information to some extent. The cosine similarity between words is calculated to obtain the semantic similarity between words, which is the prerequisite to determine whether the mapping between words can be established. We adopted the 15 terms in the data set with the smallest cosine values---the closest terms. Due to space constraints, Table 3 shows some of the results of the text analysis of professional ecommerce positions.

The semantic relations between the original input words and the first 15 most likely related words reflected in the knowledge base (as shown in Table 3) realize the semantic mapping between the original input words and the first 15 most likely related words. To measure whether the content of a certain course meets the requirements of a certain aspect (keywords), we can analyze a series of terms mapped out by the keywords and their similarities. For example, "customer relations" can be quantified by other relevant terms that appear in the course syllabus, such as "customer," "maintenance," "communication," "cooperation," "communication," "negotiation," "good maintenance," "relationship" and "satisfaction".

Based on the cluster analysis of the information of enterprises' e-commerce positions and enterprises' demands for e-commerce talents (Figure 2 and Table 3), the demands for e-commerce talents can be classified into three aspects: professional quality, professional abilities and learning capability. The details are as follows: 
(1) Professional quality. Professional quality is the sum of various abilities that people should have when engaged in a career, and it is the basic requirement for a position. As a person engaged in e-commerce work, he/she should have basic value judgment, the capacity for physical and mental adjustments, language skills, an understanding of information processing, general knowledge, etc. In addition, interpersonal skills, team cooperation, adaptability to the environment and other basic professional abilities are essential for an ecommerce career.

(2) Professional competence. All positions require ecommerce merchants to know certain modern management and network economy concepts; master the comprehensive skills of information technology and electronic services; and have a solid professional foundation and a good knowledge structure. Therefore, the professional ability of e-commerce talents can be divided into basic professional ability, professional expertise and professional application ability. Among them, basic professional abilities include economic management thinking; e-commerce engineering and technology capabilities; and e-commerce operation and management capabilities. Professional competence includes business data analysis, e-commerce innovation, cross-border e-commerce and other capabilities.

(3) Ability expansion. This reflects a demand for selfimprovement and the self-development of e-commerce talents. Its essence is innovation, which mainly includes problem-solving, innovation and decision-making. Technical positions, business positions and comprehensive management positions will encounter various problems in specific work. The level of ecommerce talent development ability determines the way and method to deal with the problems, and directly affects the actual results. E-business operation and promotion, design and other work need innovative ideas, and general management positions also need strong decision-making.

Table 3. Implementation vector similarity of Word2Vec (partial output).

\begin{tabular}{|c|c|c|c|c|c|}
\hline $\begin{array}{l}\text { Keyword } \\
\text { Group }\end{array}$ & Similar Word & Similarity & $\begin{array}{l}\text { Keyword } \\
\text { Group }\end{array}$ & Similar Word & Similarity \\
\hline \multirow[t]{15}{*}{ Team Spirit } & Bear & 0.497 & \multirow{15}{*}{$\begin{array}{l}\text { Management } \\
\text { Work }\end{array}$} & Overall & 0.462 \\
\hline & Pressure & 0.460 & & Statistics & 0.459 \\
\hline & Honest & 0.456 & & Suitable & 0.428 \\
\hline & Do the Work & 0.442 & & Operation & 0.405 \\
\hline & Rigorous & 0.416 & & Be Responsible For & 0.403 \\
\hline & Image & 0.404 & & Data Analysis & 0.362 \\
\hline & Executive Force & 0.374 & & Operation & 0.357 \\
\hline & Customer Service & 0.368 & & Keen & 0.356 \\
\hline & Spirit & 0.367 & & Maintenance & 0.344 \\
\hline & Bright & 0.361 & & \begin{tabular}{|l|} 
Development Trend \\
\end{tabular} & 0.342 \\
\hline & Detailed & 0.357 & & $\begin{array}{l}\text { Business Administration } \\
\text { and Negotiation }\end{array}$ & 0.339 \\
\hline & $\begin{array}{|ll|}\text { The Sense of } \\
\text { Responsibility }\end{array}$ & 0.349 & & \begin{tabular}{|l|l|} 
Insight & \\
\end{tabular} & 0.339 \\
\hline & Excellence & 0.347 & & Management & 0.333 \\
\hline & $\begin{array}{|ll|}\text { Bear Hardships and } \\
\text { Stand Hard Work }\end{array}$ & 0.346 & & Reception & 0.333 \\
\hline & Desire & 0.343 & & Ascension & 0.327 \\
\hline \multirow[t]{15}{*}{ Database } & SQL & 0.731 & \multirow[t]{15}{*}{ CRM } & Customer & 0.615 \\
\hline & Windows & 0.664 & & Maintenance & 0.612 \\
\hline & MYSOL & 0.663 & & $\begin{array}{|ll|}\text { Communication } & \text { And } \\
\text { Understanding } & \\
\end{array}$ & 0.498 \\
\hline & Database System & 0.627 & & Cooperation & 0.460 \\
\hline & Oracle & 0.626 & & Communication & 0.458 \\
\hline & NOSQL & 0.620 & & Negotiation & 0.447 \\
\hline & Availability & 0.600 & & Keep Well & 0.445 \\
\hline & ETL & 0.594 & & Relationship & 0.437 \\
\hline & Python & 0.570 & & Satisfaction & 0.437 \\
\hline & Algorithm & 0.548 & & Information & 0.427 \\
\hline & Proficient & 0.546 & & Intention & 0.425 \\
\hline & Data Structure & 0.532 & & Sales Strategy & 0.422 \\
\hline & AWS & 0.522 & & Search Engine & 0.418 \\
\hline & Architecture & 0.503 & & Be Responsible for & 0.417 \\
\hline & Java & 0.499 & & Find & 0.392 \\
\hline
\end{tabular}

Notes: Since the original data were Chinese text data, the similarity calculations of all terms were also based on Chinese terms. 


\subsection{Curriculum System Design}

The formation of the knowledge base provides the foundation for further realization of semantic search, and then it can further improve the consistency matching degree with the knowledge base of post competence, thus providing the basis for curriculum setting. The knowledge base can provide a multi-dimensional mapping for course selection and reflect the multidimensional personality characteristics of the course. In the actual operation, first, input the keywords of job requirements, obtain the mapping of the keywords through the job knowledge base, then calculate the overall matching degree together with the course set, and then sort the results. Finally, according to the selection criteria of the candidate set, the filtered course set is obtained. In this way, the curriculum set can effectively and quickly cover the knowledge points required for professional post competence.

Based on the results of the text analysis of the common e-commerce positions, we checked the list of existing e-commerce courses (majors). It was found that (1) job positions often require high professional quality of applicants; (2) another characteristic is that the demand for data analysis has also significantly increased. Not only database knowledge, but also business data analysis skills related to big data and cloud computing are required. The following will discuss professionalism and data analysis skills respectively.

\subsubsection{Improving professional quality}

In today's digital world, an enterprise can be able to record or collect customer information in various channels (such as social media and mobile media), so as to design a highly precise marketing strategy, and performance can be quantified [29]. Motivation is a driving force fully devoted to the development of professional competence (McGuire 2015) [30]. The increasing complexity and rapid dynamics of the business environment require the development of critical thinking (Senge 2006; Jackson 2019)[31][32]. Therefore, it is very important to cultivate students' professional qualities and social ethics. This requires students to have a good attitude. According to the 2017 Chinese e-commerce talent survey report released online by the China ECommerce Research Center, e-commerce merchants should have at least 15 qualities [29]. The top five responses from e-commerce merchants are learning ability, innovation ability, professional skills, responsibility and engagement and team work abilities (Figure 3). This shows the importance of students' attitudes and thinking in terms of job competence.

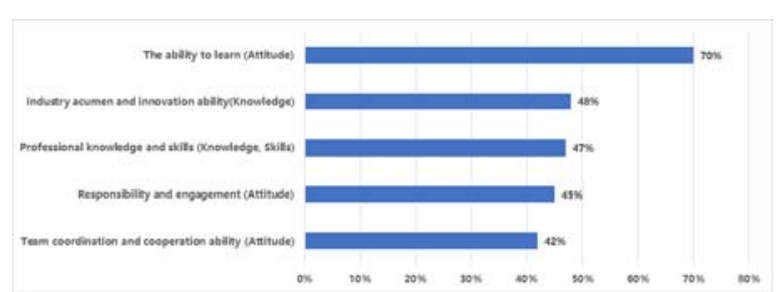

Figure 3 The top 5 qualities required by e-commerce merchants. Source: E-Commerce Research Center, China.

In order to improve professional quality, "Corporate Responsibility and Ethics" was added, and the realization of self-development was more closely linked with serving the local economy by deepening the integration of industry and education and the cooperation between schools and enterprises. Specifically, that included the following four measures: First, college teachers take temporary posts or serve as consultants to help solve the e-commerce problems of enterprises, and at the same time, enrich their own practical experience to better serve teaching. Second, senior students' internships in enterprises not only provide opportunities for students' employment, but also solve the talent problem for enterprises in advance. Third, enterprise personnel are used in colleges and universities to teach or provide training. Fourth, university--enterprise training bases and e-commerce parks. The resources of enterprises and universities are being integrated, forming long-term cooperation, and jointly cultivating e-commerce talents.

\subsubsection{Strengthening data analysis capabilities}

Data analysis is using big data technology to deeply dig and accurately analyze massive data sets with lowvalue density, so as to obtain huge commercial value. Specifically, the use of big data technology in the field of e-commerce can involve traditional and digital channels; a variety of forms of data (structured and unstructured data); and massive amounts of data collection, analysis and execution. Customers are encouraged to participate, thereby improving marketing results and measuring the process of the internal responsibility.

The teaching of an application-oriented undergraduate e-commerce specialty inevitably includes two modules: theoretical teaching and practical teaching. Although the two have independent teaching systems, they complement and promote each other. Theoretical teaching drives practical teaching, and practical teaching improves the theoretical level of the specialty.

First, theoretical teaching focuses on cultivating students' professional ability and improving students' professional knowledge. The teaching system of theoretical courses should include basic theoretical courses of e-commerce, core courses of e-commerce and courses of specialty direction. For example, basic theory courses such as computer foundation, C program, 
database design, technology and application building are offered to improve students' information processing abilities. Provide core courses such as web design and production, web design, e-commerce website construction and management to enhance students' ability for engineering e-commerce technology. We offer courses in international trade practice, foreign trade English correspondence, cross-border e-commerce and other professional directions to enhance students' professional competence.

Secondly, practice teaching focuses on cultivating students' professional ability and improving their comprehensive quality. This study thinks that the practice teaching of e-commerce specialty should include three aspects: professional cognition practice, professional knowledge practice and comprehensive application practice. Such as web design and production, website art design, cross-border e-commerce, international trade practice and other courses set professional knowledge practice content; E-commerce comprehensive practical training, e-commerce case analysis, enterprise operation management comprehensive practical training, ERP sand table simulation comprehensive practical training, online shop operation practical practice, e-commerce business planning practical practice, discipline and skill competition, graduation practice and graduation thesis and other comprehensive application practice content.

In order to cover the shortage in the field of data analysis, courses related to data analysis have been incorporated into the teaching curriculum. According to the workflow and content of data analysis, we propose adding "ETL technology," "data mining" and "big data marketing" to the curriculum system of e-commerce majors toward Sustainable Development Goals, and to build the bridge with the jobs out there.

\section{CONCLUSIONS}

The teaching of talents of e-commerce is a complex system. Application-oriented colleges and universities must take the needs of enterprises and society as guidance, take the training of students for professional applications as the core and establish an open and competencecentered teaching system. In this paper, 240,000 job descriptions related to e-commerce, data and the Internet were taken as the research object. By using a skip-gram neural network model to calculate word vector similarities, we mapped relationships between keywords in different industries, and semantically similar entry sets were established to form a job knowledge base. This study found that quality vocational education and data analysis are often ignored by the traditional curriculum of e-commerce. For the e-commerce major, these two points are important for useful education. The knowledge base established in this study aims to solve the mismatches between recruitment requirements and the course, which should be considered a theoretical innovation and have practical utility. It connects social demand with university teaching, provides some reference for universities to set up intelligent courses and promotes the realization of Sustainable Development Goals.

\section{ACKNOWLEDGMENTS}

I would like to thank Qi Ma, who brought helpful advice, and to thank Zeng Zeming, who helped with some of the data collection and processing. This research was funded by Guangdong Provincial Department of Education, grant number 57-JY191401, and China Vocational Competency Certification, grant number CVCC19140.

\section{REFERENCES}

[1] Sustainable Development Goals. Available online: https://sustainabledevelopment.un.org/ (accessed on 20 March 2021).

[2] R. Lozano, Envisioning sustainability threedimensionally. J. Clean. Prod. 2008,16, 1838-1846.

[3] D. Setó-Pamies, E. Papaoikonomou, A Multi-level Perspective for the Integration of Ethics, Corporate Social Responsibility and Sustainability (ECSRS) in Management Education. J Bus Ethics 2016,136, 523-538.

[4] V. Piza, J. Aparicio, C. Rodríguez, R. Marín, J. Beltrán, R. Bedolla, Sustainability in Higher Education: A Didactic Strategy for Environmental Mainstreaming. Sustainability 2018, 10(12), 4556. DOI: https://doi.org/10.3390/su10124556.

[5] T. Ferguson, C.G. Roofe, SDG 4 in higher education: Challenges and opportunities. International Journal of Sustainability in Higher Education, 2020, Vol. 21 No. $\quad 5, \quad 959-975 . \quad$ DOI: https://doi.org/10.1108/IJSHE-12-2019-0353.

[6] Y. LeCun, Y. Bengio, G. Hinton, Deep learning. nature, 2015, 521(7553), 436-444.

[7] G.E. Hinton, R.R. Salakhutdinov, Reducing the dimensionality of data with neural networks. science, 2006,313(5786), 504-507. DOI: 10.1126/science.1127647

[8] Z.S. Harris, Distributional structure. Word, 1954, 10(2-3), 146-162.

[9] P.F. Brown, V.J. Della Pietra, P.V. Desouza, J.C. Lai, Mercer, R.L. Class-based n-gram models of natural language. Computational linguistics, 1992, 18(4), 467-480.

[10] S. Dagan, Marcus, S. Markovitch, Contextual word similarity and estimation from sparse data. In 31st 
Annual Meeting of the Association for Computational Linguistics, 1993, June. 164-171.

[11] Dagan, L. Lee, F.C. Pereira, Similarity-based models of word cooccurrence probabilities. Machine learning, 1999, 34(1-3), 43-69.

[12] Y. Bengio, R. Ducharme, P. Vincent, C. Jauvin, A neural probabilistic language model. Journal of machine learning research, 2003, 3(Feb), 1137-1155.

[13] S. Lai, L. Xu, Y. Chen, K. Liu, Zhao, J. Chinese Word Segment Based on Character Representation Learning. Journal of Chinese Information Processing, 2013,27(5), 8-15. DOI: CNKI:SUN:MESS.0.2013-05-002

[14] R.H. Hall, A. O'Donnell, Cognitive and affective outcomes of learning from knowledge maps. Contemporary educational psychology, 1996, 21(1), 94-101.

[15] K.W. McCain, J.M. Verner, G.W. Hislop, W. Evanco, V. Cole, The use of bibliometric and knowledge elicitation techniques to map a knowledge domain: Software engineering in the 1990s. Scientometrics, 2005, 65(1), 131-144. DOI: https://doi.org/10.1007/s11192-005-0262-7.

[16] F. Janssens, P. Glenisson, W. Glänzel, B. De Moor, Co-clustering approaches to integrate lexical and bibliographical information. In Proceedings of the 10th international conference of the International Society for Scientometrics and Informetrics (ISSI). 2005, Vol. 1, 284-289.

[17] Hai-Yan Hou, Ze-Yuan Liu, Yue Chen, Chun-Lin Jiang, Li-Chun Yin, Jie Pang, Mapping of Science Studies: The Trend of Research Fronts. Science Research Management, 2006, 27(3), 90-96. DOI: 10.19571/j.cnki.1000-2995.2006.03.014.

[18] Q. Zhang, Text mining technology and its application in patent information analysis. Journal of Modern Information, 2006, 26(3), 209-210.

[19] Y. Chen, X. Wang, G. Zheng, Theory Fronts Research Based on Mapping Knowledge Domain. Studies in Science of Science, 2007, 25(6), 22-28. DOI: 10.16192/j.cnki.1003-2053.2007.s1.025.

[20] P. Du, T. Wu, C. Wang, The Knowledge Mapping Analysis of the Research Areas of Human Resource for Science and Technology. Forum of Science and Technology in China, 2013, 1(8), 83-89. DOI: 10.13580/j.cnki.fstc.2013.08.014.

[21] R. Rao, C. Duan, Intellectual Structure and Development Trends of Human Resource Business Partner Model Research: Based on the Analysis of Mapping Knowledge Domains. Foreign Economics
\& Management, 2017, 39(4), 98-116. DOI: 10.16538/j.cnki.fem.2017.04.008.

[22] F H. ang, Y. Dai, Overview of HRST Based on Knowledge Mapping. Science \& Technology Progress and Policy, 2010, 27(9), 153-156.

[23] H. Fang, The Evolution History of Research Focusing on Human Resources Management for 40 Years Based on Knowledge Map. East China Economic Management, 2013, 27(8), 110-117. DOI: 10.3969/j.issn.1007-5097.2013.08.023.

[24] S. Zhao, Z. Zhang, W. Chen, Mapping Knowledge Domain and Prospects of HRM Research in the 70 Years since the Founding of the People's Republic of China. Business Management Journal, 2019, 41(7), 190. DOI: 10.19616/j.cnki.bmj.2019.07.012.

[25] T. Mikolov, I. Sutskever, K. Chen, G.S. Corrado, Dean, J. Distributed representations of words and phrases and their compositionality. In Advances in neural information processing systems, 2013, 31113119.

[26] Y. Zhu, E. Yan, F. Wang, Semantic relatedness and similarity of biomedical terms: examining the effects of recency, size, and section of biomedical publications on the performance of word2vec. BMC medical informatics and decision making, 2017, 17(1), 1-8. DOI: https://doi.org/10.1186/s12911-017-0498-1.

[27] X. Chengzhang, L. Dan, Chinese text summarization algorithm based on word2vec. In Journal of Physics: Conference Series (Vol. 976, No. 1, p. 012006),2018. IOP Publishing. DOI: 10.1088/1742-6596/976/1/012006.

[28] H. Zhao, D. Cai, C. Huang, C. Kit, Chinese word segmentation: Another decade review (2007-2017). 2019, arXiv preprint arXiv:1901.06079.

[29] CECRC. Annual Survey Report on China's ECommerce Talents Publisher: China E-commerce Research Center, China, 2018.

[30] S.Y. McGuire, Teach students how to learn: Strategies you can incorporate into any course to improve student metacognition, study skills, and motivation Publisher: Stylus Publishing, LLC., USA, 2015.

[31] P.M. Senge, The Fifth Discipline: The Art and Practice of the Learning Organization, 3rd ed. Publisher: Broadway Business, USA, 2006.

[32] M.C. Jackson, Critical Systems Thinking and the Management of Complexity Publisher: JohnWiley \& Sons: Hoboken, NJ. USA, 2019. 